\title{
Prevalence of gallstones in relation to differing treatment rates for biliary disease
}

\author{
L. J. OPIT AND S. GREENHILL \\ Health Services Research Centre, Department of Social Medicine, Medical School, University of Birmingham B15 2TJ \\ and \\ Department of Community Medicine, Medical School, University of Alberta, Edmonton, Canada
}

\section{SUMMARY}

This paper attempts to deduce the prevalence of gallstones by the use of previously published necropsy data. These data are interpreted as suggesting that the incidence of gallstone development is similar in North America, Australia, Great Britain, and Norway and is largely independent of age between the third and eighth decades.

Data are also presented which may imply that the total mortality for gallstones or non-malignant gallbladder disease is not greatly influenced by increasing the treatment rate from the present level in the United Kingdom.

It is believed that this evidence does not support the view that widely differing treatment rates for gallstones reflect differences in the prevalence of the disease.

\section{INTRODUCTION}

It has been known for some time that the surgical admission and treatment rates for biliary disease are much greater in North America than in the United Kingdom. Recently, Plant et al. (1973) compared the cholecystectomy rates in three similar cities in Canada, England, and France over a 10-year period. They found that the cholecystectomy rate was six times higher in the Canadian city and, if patients under 35 years only were considered, this difference increased to a factor of nine.
They inferred that these observations reflected mainly a widely differing prevalence of the disease of cholelithiasis. It is clear that other explanations may exist and these might be related to different rates of clinical or radiological investigation in the populations or different indications for surgical treatment. It is likely that these two factors are not independent of one another.

This paper attempts to assess, from previouslyo published necropsy data, the likely contribution which variations in the prevalence of gallstones might make to the treatment rates and offers some speculations about surgical indications as these are reflected by the mortality rates of gallbladder disease.

\section{MethoD}

The necropsy data are taken from papers published by Gross (1929), Cleland (1953), Lieber (1952), and Torvick and Hoivik (1960-1961). The source, number of necropsies, and time span of these studies are summarized in Table $I$.

\section{RESULTS}

Any hospital necropsy survey giving the prevalence of gallstones by age must present certain difficulties when used to estimate the frequency of the disease in the general population:

TABLE I

\begin{tabular}{|c|c|c|c|c|c|}
\hline \multicolumn{2}{|c|}{ Author } & Country & Data Analysed & Time Period & No. \\
\hline Gross (1929) & .. & Britain & All necropsies & $1893-1920$ & 9,000 \\
\hline Cleland (1953) & .. & Australia & All necropsies & $1920-1948$ & 7,000 \\
\hline Lieber (1952) & .. & USA & $\begin{array}{l}\text { Necropsy results used } \\
\text { from white races only }\end{array}$ & 1920-1949 & 34,666 (total) \\
\hline \multicolumn{2}{|c|}{ Torvick and Hoivik (1960-1961) } & Norway & $\begin{array}{l}\text { Necropsy results from } \\
\text { white races only } \\
\text { ( } 50 \% \text { of all deaths in } \\
\text { Oslo) }\end{array}$ & 1952-1957 & 11,129 \\
\hline
\end{tabular}


(1) The results relate to the prevalence of cholelithiasis in patients who have died and clearly, because these patients are selected, they cannot be representative of the population as a whole. This is particularly true of the younger age groups in hospital since these will have a low mortality rate, and the presence of gallstone complications or symptoms will obviously increase the chance that they will enter the series. This will falsely elevate the prevalence.

(2) For the necropsy study to be useful it must contain a large number of necropsies and hence will need to be collected over many years. Thus any secular change in prevalence dependent on environmental, dietary or population change is obscured.

(3) The loss of gallstones from previous cholecystectomy or cholecystotomy will be difficult to assess unless these details are provided. In only one of the necropsy series cited were these data available (Torvick and Hoivik, 1960-1961).

Nevertheless when the data are plotted by the age mid-point of decades some observations and deductions can be made.

In Fig. 1 we have plotted the percentage of women with gallstones in the four necropsy series. The graph shows a consistent increase in prevalence with age from the third to the eighth decade. The divergence between the prevalence figures from individual series can be measured by the ratio of the total range for each age to the average value for that point. At the 25 -year point this ratio is $1 \cdot 3$ and falls steadily to 0.3 at age 75 . The proportionate differences between the respective series gradually lessen from the 40-49 age group onward and the differences probably reflect the nature of populations

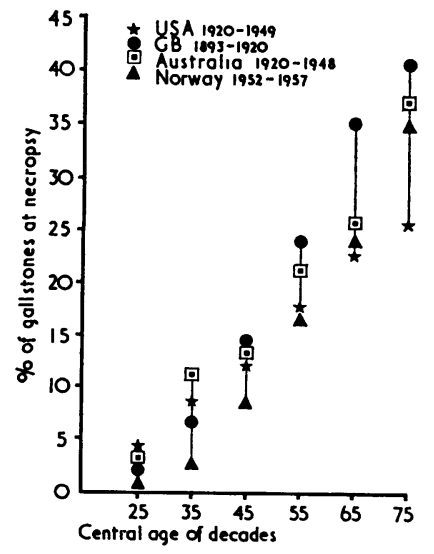

Fio. 1 Prevalence of gallstones in women at necropsy sampled rather than any significant difference in the disease prevalence in the four countries represented.

The most reliable data probably come from the Norwegian figures since these are derived from $50 \%$ of all deaths which occurred in Oslo during the survey period. One other feature of the graph may be important. Every series of necropsies shows a linear relationship between the percentage of cases of gallstones and age. The linear hypothesis was examined by least squares fitting and showed an excellent correlation for all series. With this hypothesis the slopes give a very rough measure of the incidence rate if we can assume that:

(1) cohort effects and sampling problems can be neglected;

(2) stones cannot spontaneously disappear, and those removed surgically are relatively few in number although this second assumption becomes increasingly difficult to accept with data relating to deaths since 1950 .

The coefficients and goodness of fit are summarized in Table II. Using the linear regression associated with the average prevalence values at each age point gives

$$
Y=0.68 X-15 \cdot 8
$$

where $Y=$ percentage of persons with stones and $\mathrm{X}$ is the age in years. Thus the 10-year incidence rate from this approach is deduced as 68 per 1,000 women. The linear hypothesis implies that the incidence rate of gallstones is independent of age, and the conclusion does not parallel the measured risk rates of treatment for gallstones in North America by age (Plant et al., 1973).

The results for males are shown in Figure 2. This shows that at every age the chance of developing stones is less in men, an observation certainly in accord with data taken from treatment records. The divergence at each age point is less than that seen with the data from females, and there is a general reduction of divergence ratios from 0.86

TABLE II

LINEAR FUNCTION FITTING FOR PREVALENCE OF GALLSTONES IN WHITE FEMALES

\begin{tabular}{|c|c|c|c|c|}
\hline \multirow[b]{2}{*}{ Series } & \multicolumn{2}{|c|}{ Equation Coefficients } & \multirow[b]{2}{*}{$\begin{array}{l}\text { Correlation } \\
\text { Coefficients }\end{array}$} & \multirow{2}{*}{$\begin{array}{c}\text { Deduced } \\
10 \text { year } \\
\text { Incidence } \\
\text { Rate/1,000 }\end{array}$} \\
\hline & $\begin{array}{c}\text { Slope } \\
\text { (cases/100 } \\
\text { persons/yr) }\end{array}$ & Intercept & & \\
\hline $\begin{array}{l}\text { Britain } \\
\text { Australia } \\
\text { USA } \\
\text { Norway } \\
\text { Average } . .\end{array}$ & $\begin{array}{l}0.82 \\
0.63 \\
0.57 \\
0.68 \\
0.68\end{array}$ & $\begin{array}{l}-20.4 \\
-12.9 \\
-10.8 \\
-19.2 \\
-15.8\end{array}$ & $\begin{array}{l}r=0.99 \\
r=0.98 \\
r=0.98 \\
r=0.97 \\
r=0.99\end{array}$ & $\begin{array}{l}82 \\
63 \\
57 \\
68 \\
68\end{array}$ \\
\hline
\end{tabular}




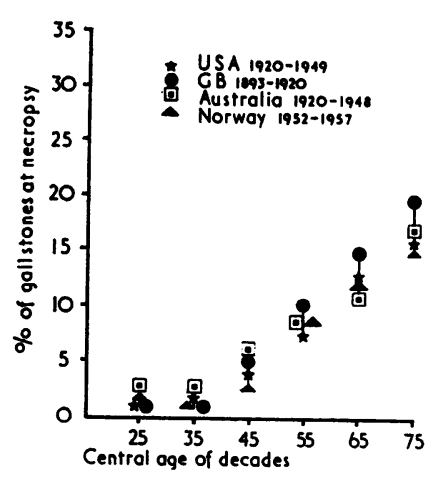

Fig. 2. Prevalence of gallstones in men at necropsy.

at 25 years to 0.22 at 75 years. The data show no clear evidence of any marked difference in prevalence between the individual series.

The linearity of prevalence with age is also obvious from the third decade onward and the average values corresponding to the line

$$
Y=0 \cdot 33 X-8 \cdot 7
$$

$(r=0.98)$, where $Y$ and $X$ have the same meaning as before. Thus with the assumptions made earlier the 10-year incidence rate per thousand men would be 33 , which is about $50 \%$ of the rate found in women. As we have indicated earlier, these incidence rates are based on many assumptions but the most difficult to accept is the possibility that there is no cohort change. It is interesting therefore to compare these data with those obtained in North America during the Framingham study (Friedman, Kannel, and Dawber, 1966) which relied on following cohorts of men and women during a 10-year period. The diagnosis of gallstones in this later study depended on a patient complaining of symptoms and presenting to a doctor who recognized the possibility of gallstones as the cause of symptoms which were then investigated accordingly.

The incidence rates from this study are set out in Table III. They do not agree with age-independent linearity deduced from our analysis of the necropsy

TABLE III

INCIDENCE OF GALLSTONES IN THE FRAMINGHAM

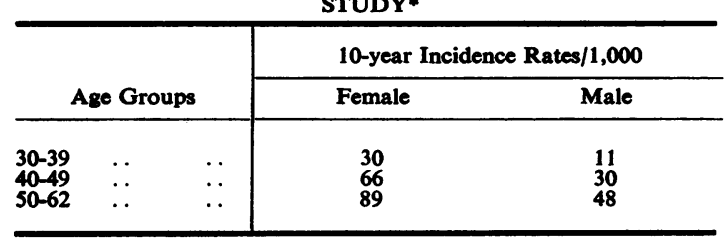

*From Friedman et al. (1966) data but the rates for the fifth and sixth decades $\stackrel{\infty}{\infty}$ are certainly similar to the incidence rate we have $O$ deduced. However, as we have suggested, this $z$

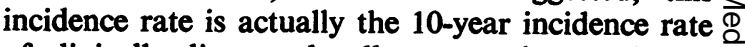
of clinically diagnosed gallstones and as such will include important factors related to both the symptoms and investigation. Unfortunately we have $\overline{0}$ not been able to discover a similar study carried 흐 out in Europe with which to compare these results. $\frac{\text { क }}{2}$

Thus, in summary, we believe that the necropsy $\stackrel{\mathbb{\Omega}}{\propto}$ data do not disclose any major difference in the prevalence of cholelithiasis between Europe and $\rightarrow$ North America and that from the third decade? onward there is close to a linear relationship $\overrightarrow{\vec{\omega}}$ between age and prevalence of gallstones in both $\stackrel{\omega}{\mathcal{S}}$ men and women. These data would certainly not $\bar{D}$ support the view expressed by Plant et al. (1973) $\stackrel{\rho}{?}$ that there is a very large difference of the order $\infty$ of sixfold in the prevalence of cholelethiasis between North America and Europe, although $\mathcal{O}$ clearly some small difference would still be possible.

\section{MoRTAlity from Biliary Disease}

In their discussion Plant et al. (1973) claim that the indications for surgical treatment of biliar? disease are identical in the three cities examined However, they produce no evidence to supporf this claim. There is one method of examining the indications for treatment in a more general sense. and that is by comparing the treatment rate for the disease (as a function of population) with mortality rate as a function of the admission or treatment rate. As the surgical treatment rate rises we would expect the mortality per treatment to fall, eventually becoming asymptotic to the mortality rate of the treatment itelf. In Fig. 3 we have plotted points corresponding to data for England and Wales in the period 1961-71 using

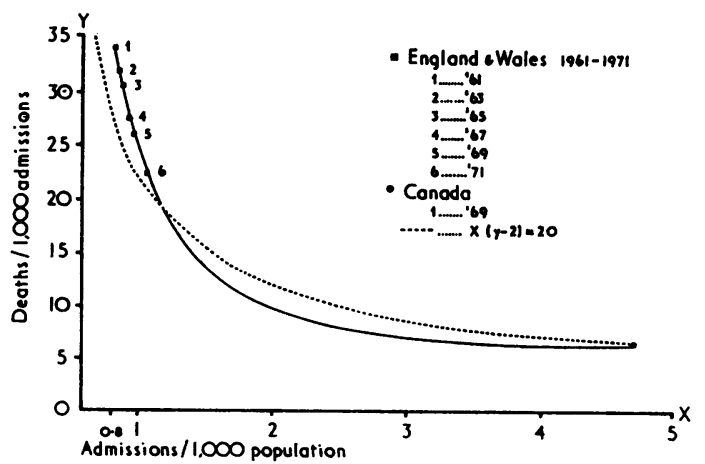

Fig. 3. Relation of hospital death rate for biliary disease to admission rate. 
data from the Reports on Hospital Inpatient Enquiry (Department of Health and Social Security, 1971) and added a point corresponding to the effect of high admission rates from Canadian data (Canada, Minister of Industry, Trade and Commerce, 1970). Admission rates have been used to construct the figure since surgical treatment rates are not available for Canada in this report. In general, the surgical treatment rate will be about $75 \%$ of the admission rate. It has not been possible to date to find admission rates giving intermediate points.

The points have been joined by a smooth monotonically decreasing curve which lies close to one branch of the hyperbola $\mathrm{X}(\mathrm{Y}-2)=20$ with an asymptote at $Y=2.0$ corresponding in our model to an admission mortality of $0.2 \%$. This is very close to the operative mortality of cholecystectomy in uncomplicated cases reported for both the United Kingdom and the United States (Selzer and Rosato, 1970; Maingot, 1963). If the points actually lie on a hyperbola between the limits shown then this would imply that the mortality from gallbladder disease per 1,000 persons in the population is unchanged by advancing the treatment rate. This statement is obviously incorrect if it is made with respect to individual cases but does suggest that the benefits from reduction in disease mortality from surgical treatment will be balanced quickly by the mortality of the treatment itself. If we assume that the average level of technical competence and the standards of surgical care are similar in Canada and the United Kingdom, the higher mortality rates per admission in the United Kingdom suggest that the indications in this gross sense anyway are indeed dissimilar. This is confirmed further by the younger age profile of the admissions in Canada. One major cause for difference in the treatment rates remains unexplored and this relates to initial presentation, selection, and investigation of patients complaining of abdominal symptoms. We are aware of no comparative data that would allow this question to be examined.

\section{Discussion}

The main purpose of this paper is to assess from earlier published necropsy data the possible contribution which differences in gallstone prevalence made to differing treatment rates for biliary disease. We have concluded from our analysis that it is unlikely to be significant. The belief that other factors are mainly responsible is supported by data published by Vayda (1973), which show higher surgical rates in Canada for many diseases or procedures unrelated to cholelithiasis.
It is not possible to exclude some differences in the prevalence of gallstones among different populations, particularly as necropsy data from Japan and Singapore show it to be much lower in these countries (Hwang, 1970; Nakayama and Miyake, 1970), while studies among the Pima Indians (Comess, Bennett, and Burch, 1967) suggest that the prevalence of gallstones is much higher in this ethnic group.

One major problem in the arguments advanced in this paper is that they ignore the possibility of recent change in prevalence, particularly since it is known that treatment rates have been rising since 1948 (Holland and Heaton, 1972; Milner and Hewitt, 1972). We have no reliable recent necropsy data comparable with the earlier series examined. If they did exist interpretation would be made difficult because the cholecystectomy rate has risen. We cannot exclude therefore the possibility that there has been a recent increase in the prevalence of cholelithiasis. It does seem, however, unlikely that this has occurred with marked geographical selectivity among European racial types. The prevalence and types of gallstones among the Japanese are known to be changing, and this effect is possibly associated with an increased intake of calories. Nevertheless we believe that the data presented here, though imperfect, support the contention that the marked differences in treatment rates for gallbladder disease require some explanation other than differences in prevalence. We would suggest, further, that the explanation will be concerned with the earliest stages in the presentation and diagnosis of the disease. If the prevalence of gallstones is as high as the necropsy data suggest, then it is likely that enthusiastic investigation of any group of persons complaining of minor abdominal symptoms will reveal a significant proportion with radiological evidence of gallstones. The mortality data which are presented suggest that the value of surgical treatment to some of these persons is uncertain.

We wish to thank the Department of Health and Welfare, Ottawa, Canada, for providing a National Health Grant to one of us (L.J.O.).

\section{REFERENCES}

Canada, Minister of Industry, Trade and Commerce (1970). Hospital Morbidity 1969, Catalogue 82-206. Ottawa, Statistics Canada.

Cleland, J. B. (1953). Gallstones in seven thousand post-mortem examinations. Med. J. Aust., 2, 488.

Comess, L. J., Bennett, P. H., and BurCh, T. A. (1967). Clinical gallbladder disease in Pima Indians. New Engl. J. Med., 277, 894. 
Department of Health and Social Security (1971). Report on Hospital In-patient Enquiry, Part 1. HMSO, London.

Friedman, G. D., Kannel, W. B., and Dawber, T. R. (1966). The epidemiology of gallbladder disease: Observations in the Framingham study. J. chron. Dis., 19, 273.

Gross, D. M. B. (1929). A statistical study of cholelithiasis. J. Path. Bact., 32, 503.

Holland, C. and Heaton, K. W. (1972). Increasing frequency of gallbladder operations in the Bristol clinical area. Brit. Med. J., 3, 672.

Hwang, W. S. (1970). Cholelithiasis in Singapore. Gut, 11, 141.

LIEBER, M. M. (1952). The incidence of gallstones and their correlation with other diseases. Ann. Surg., 135, 394.

MaINGot, R. H. (1963). Complications of cholecystectomy. Ann. roy. Coll. Surg. Engl., 32, 42.
Milner, J. and Hewitr, D. (1972). The occurrence and treatment of gallbladder disease in Ontario. $J$. chron. Dis., 25, 73.

Nakayama, F. and Miyake, H. (1970). The changing state of gallstone disease in Japan. Amer. J. Surg., $120,794$.

Plant, J. C. D., Percy, I., Bates, T., Gastard, J., and DE NERCY, H. Y. (1973). Incidence of gallbladder disease in Canada, England and France. Lancet, 2, 249.

Selzer, M. H. and Rosato, F. E. (1970). Mortality following cholecystectomy. Surg. Gynec. Obstet. 130, 64.

ToRvick, A. and Horvik, B. (1960/1961). Gallstones in an autopsy series. Act. chir. Scand., 120, 168.

VAYDA, E. (1973). A comparison of surgical rates in Canada and in England and Wales. New. Engl. J. Med., 289, 1224. 